\title{
The impact of Objective Mathematical Analysis during Fractional Flow Reserve measurement: results from the OMA-FFR study
}

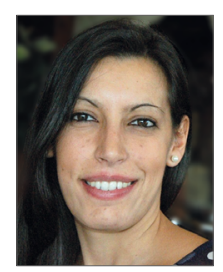

Martina I. Sciola ${ }^{1,2}$, MEng, PhD; Paul D. Morris ${ }^{1,2,3 *}$, PhD, MRCP; Rebecca Gosling ${ }^{1,2,3}, \mathrm{MBChB}, \mathrm{MRCP}$; Patricia V. Lawford ${ }^{1,2}, \mathrm{BSc}, \mathrm{PhD}$; D. Rodney Hose ${ }^{1,2,4}$, BSc, PhD; Julian P. Gunn ${ }^{1,2,3}$, MD, MRCP

1. Mathematical Modelling in Medicine Group, Department of Infection, Immunity and Cardiovascular Science, University of Sheffield, Sheffield, United Kingdom; 2. Insigneo Institute for In Silico Medicine, University of Sheffield, Sheffield, United Kingdom; 3. Department of Cardiology, Sheffield Teaching Hospitals NHS Foundation Trust, Sheffield, United Kingdom; 4. Department of Circulation and Medical Imaging, Norwegian University of Science and Technology (NTNU), Trondheim, Norway

P.D. Morris and M.I. Sciola contributed equally to this work.

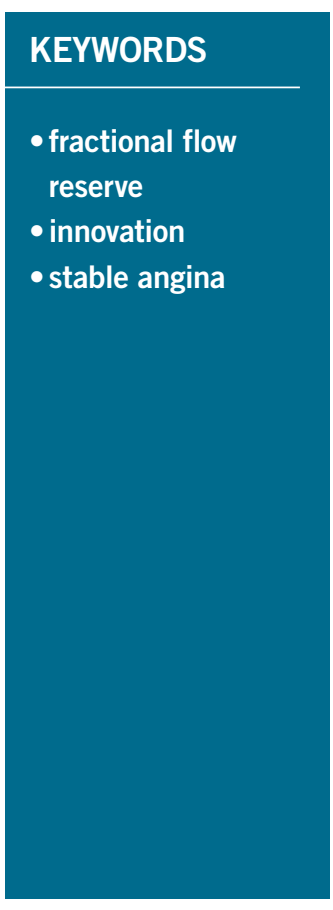

\section{Abstract}

Aims: Fractional flow reserve (FFR), the reference standard for guiding coronary revascularisation, is most commonly acquired during intravenous adenosine infusion. Results may be sensitive to system- and operator-dependent variability in how pressure data are analysed and interpreted. To quantify FFR objectively, we developed a computational protocol to process the recorded pressure signals in a consistent manner. We studied the impact on lesion (re)classification and compared this with the operator-selected FFR obtained during cardiac catheterisation.

Methods and results: The algorithm used a moving average and Fourier transformation to identify the $\mathrm{P}_{\mathrm{d}} / \mathrm{P}_{\mathrm{a}}$ ratio at its nadir $\left(\mathrm{FFR}_{\min }\right)$ and during the stable hyperaemic period $\left(\mathrm{FFR}_{\text {stable }}\right)$ in $<2 \mathrm{~s}$ with $100 \%$ repeatability, in 163 coronary stenoses ( 93 patients). The mean operator-selected FFR ( $\mathrm{FFR}_{\mathrm{CL}}$ ) was higher than $\mathrm{FFR}_{\min }$ and lower than $\mathrm{FFR}_{\text {stable }}(0.779$ vs. 0.762 vs. $0.806, \mathrm{p}=<0.01)$. Compared with $\mathrm{FFR}_{\min }, \mathrm{FFR}_{\text {stable }}$ resulted in $16.5 \%$ of all lesions being reclassified, all from significant to non-significant $(\mathrm{p}<0.01)$. $\mathrm{FFR}_{\mathrm{CL}}$ classified lesion significance differently from both $\mathrm{FFR}_{\text {stable }}$ and $\mathrm{FFR}_{\min }(11.7 \%$ and $6.1 \%$ lesions reclassified, respectively, $\mathrm{p}<0.01)$.

Conclusions: Subtle differences in how pressure data are analysed and interpreted by the operator during adenosine infusion result in significant differences in the classification of physiological lesion significance. An algorithmic analysis may be helpful in standardising FFR analysis, providing an objective and repeatable result. 


\section{Abbreviations}

CAD coronary artery disease

CAG coronary angiography

FFR fractional flow reserve

$\mathbf{F F R}_{\mathrm{cL}}$ the value of $\mathrm{P}_{\mathrm{d}} / \mathrm{P}_{\mathrm{a}}$ documented as the fractional flow reserve by the operator in the catheterisation laboratory during the procedure

FFR $_{\text {min }}$ the minimum value of $\mathrm{P}_{\mathrm{d}} / \mathrm{P}_{\mathrm{a}}$ achieved during adenosine infusion

FFR $_{\text {stable }}$ the value of $\mathrm{P}_{d} / \mathrm{P}_{\mathrm{a}}$ during the stable period of hyperaemia adenosine infusion

FFT fast Fourier transformation

LAD left anterior descending artery

LCX left circumflex artery

PCI percutaneous coronary intervention

$\mathbf{P}_{\mathrm{a}} \quad$ proximal aortic pressure

$\mathbf{P}_{\mathrm{d}} \quad$ distal coronary pressure

RCA right coronary artery

\section{Introduction}

Standard coronary angiography (CAG) is subjective and does not reliably identify ischaemia-causing lesions ${ }^{1,2}$. Fractional flow reserve (FFR) is a more objective measure of physiological lesion significance in the cardiac catheterisation laboratory ${ }^{3,4}$ and, when used to guide percutaneous coronary intervention (PCI), reduces adverse cardiac events compared with angiographic guidance alone ${ }^{5}$. When performing FFR, hyperaemia is usually achieved with an intravenous infusion of adenosine. Sixty to ninety seconds after adenosine infusion is commenced, the proximal and distal pressures $\left(\mathrm{P}_{\mathrm{a}}\right.$ and $\left.\mathrm{P}_{d}\right)$ begin to rise and then fall ${ }^{6}$. During this phase, the difference between the proximal $\left(\mathrm{P}_{\mathrm{a}}\right)$ and distal $\left(P_{d}\right)$ is maximal and the FFR is minimal. Subsequently, the FFR stabilises at a slightly higher level, namely maximal stable hyperaemia ${ }^{6}$.

In the cardiac catheterisation laboratory, FFR analysers provide a real-time $\mathrm{P}_{\mathrm{d}} / \mathrm{P}_{\mathrm{a}}$ readout. Most systems log and display the minimum $\mathrm{P}_{\mathrm{d}} / \mathrm{P}_{\mathrm{a}}$ value encountered during an analysis ("run") in which the pressure wire is positioned across a coronary artery lesion. Operators may review the $\mathrm{P}_{\mathrm{d}} / \mathrm{P}_{\mathrm{a}}$ traces by moving a cursor along the time course of the recordings, choosing a value of $\mathrm{P}_{d} / \mathrm{P}_{\mathrm{a}}$ to record as the FFR (Figure 1). This is then used to guide treatment decisions. However, the FFR result is sensitive to variability in how and when the $P_{d} / P_{a}$ signal is processed and interpreted. During the administration of adenosine, several phases are observed in the $P_{a}$ and $P_{d}$ signals caused by sequential pulmonary, coronary and systemic arteriolar vasodilation with physiological compensation by the cardiovascular regulatory mechanisms. Eventually, these components equilibrate and a stable phase of coronary hyperaemia is achieved ${ }^{6-9}$. Typically, three key phases are observed sequentially in the $\mathrm{P}_{\mathrm{d}} / \mathrm{P}_{\mathrm{a}}$ signal (Figure 1) during FFR measurement:

- "baseline" $-\mathrm{P}_{d} / \mathrm{P}_{\mathrm{a}}$ ratio prior to adenosine administration

- "peak response" - when $P_{d} / P_{a}$ reaches its minimum value $\left(F\right.$ min $\left.{ }_{\text {min }}\right)$

- "stability" - during hyperaemia but when $\mathrm{P}_{\mathrm{d}} / \mathrm{P}_{\mathrm{a}}$ is stable $\left(\mathrm{FFR}_{\text {stable }}\right)$
Typically, when the $\mathrm{P}_{\mathrm{d}} / \mathrm{P}_{\mathrm{a}}$ ratio falls, it reaches its lowest value and then stabilises at a higher level as the period of stable maximal hyperaemia ${ }^{6,8}$. Some experts support the measurement of FFR during the period of stable hyperaemia ${ }^{6,10}$, whereas others support the use of the minimal acquired value of the $\mathrm{P}_{\mathrm{d}} / \mathrm{P}_{\mathrm{a}}$ ratio ${ }^{7,11}$. Differences between these two approaches may affect the FFR result and even the classification of physiological lesion significance ${ }^{10}$. How the analyser systems are set up to average the raw $\mathrm{P}_{\mathrm{d}} / \mathrm{P}_{\mathrm{a}}$ data (i.e., over an arbitrary number of cardiac cycles) may also affect the FFR result by smoothing the signal. An element of subjectivity may also be introduced when the operators review the $\mathrm{P}_{\mathrm{d}} / \mathrm{P}_{\mathrm{a}}$ trace to determine the FFR because this process may be hampered by instability or artefactual aberrations in the signal. Thus, whilst a major strength of FFR is its objectivity, an element of subjectivity may still cloud its interpretation.

In this study we demonstrate a mathematical algorithm which objectively analyses the $\mathrm{P}_{\mathrm{d}} / \mathrm{P}_{\mathrm{a}}$ signal to standardise FFR measurement. The algorithm was used to identify the $\mathrm{P}_{\mathrm{d}} / \mathrm{P}_{\mathrm{a}}$ nadir $\left(\mathrm{FFR}_{\min }\right)$ and the $\mathrm{P}_{\mathrm{d}} / \mathrm{P}_{\mathrm{a}}$ during the stable period of hyperaemia $\left(\mathrm{FFR}_{\text {stable }}\right)$ (Figure 1). These were compared with each other and with the operator-selected FFR, chosen in the cardiac catheterisation laboratory during the procedure. We then studied the impact of each approach on physiological lesion classification, in a real-world cohort of patients with coronary artery disease (CAD).

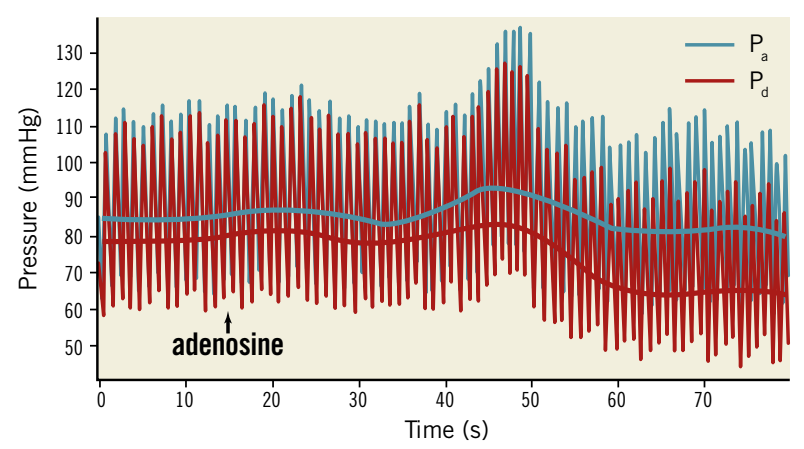

Figure 1. An example of the proximal and distal pressure $\left(P_{a}\right.$ and $\left.P_{d}\right)$ response to intravenous adenosine. Raw pressure data are demonstrated. The solid lines represent the means of the $P_{a}$ and $P_{d}$.

\section{Methods}

\section{STUDY LOCATION}

Data were collected at the South Yorkshire Cardiothoracic Centre, Sheffield Teaching Hospitals NHS Foundation Trust, Sheffield, UK, and analysed at the University of Sheffield, UK. All work was approved by the NHS Research Ethics Committee. Participating patients provided informed consent.

\section{CLINICAL DATA}

Consecutive patients with chronic stable coronary artery disease with at least one stenosis between $50-90 \%$ by visual analysis of the angiogram were recruited and studied prospectively with FFR. Exclusion criteria were serious comorbidity, inability to provide informed consent, chronic total occlusion, acute presentation 
within 60 days, and intolerance of intravenous adenosine, nitrate, or iodine-based contrast media. FFR assessment was measured with the PrimeWire PRESTIGE ${ }^{\circledR}$ (Volcano Corporation, San Diego, CA, USA) or PressureWire ${ }^{\mathrm{TM}} \mathrm{X}$ guidewire (St. Jude Medical, St. Paul, MN, USA) systems. Hyperaemia was induced by a central intravenous infusion of adenosine at $140 \mu \mathrm{g} / \mathrm{kg} / \mathrm{min}$ ensuring no $\mathrm{P}_{\mathrm{a}}$ ventricularisation or $\mathrm{P}_{\mathrm{d}}$ signal drift. FFR was recorded by the operator as the value judged to represent the $\mathrm{P}_{d} / \mathrm{P}_{\mathrm{a}}$ nadir as originally described ${ }^{11}$. All pressure data were recorded for at least two minutes, until stable hyperaemia had been achieved. Physiological lesion significance was defined as FFR $\leq 0.80$ and operators interpreted the FFR as the nadir of the $\mathrm{P}_{\mathrm{d}} / \mathrm{P}_{\mathrm{a}}$ trace during maximal hyperaemia, according to the methods originally described by De Bruyne et $\mathrm{al}^{5}$. This measurement, as documented in the medical notes by the operators during the procedure, was referred to as the catheter laboratory FFR $\left(\mathrm{FFR}_{\mathrm{CL}}\right)$. PCI was guided by the $\mathrm{FFR}_{\mathrm{CL}}$ result. After PCI, FFR was repeated to ensure an optimum physiological result.

\section{THE MATHEMATICAL ALGORITHM}

The novel algorithm identified values representing each of these phases using the $\mathrm{P}_{d} / \mathrm{P}_{\mathrm{a}}$ signal. Raw $\mathrm{P}_{\mathrm{a}}$ and $\mathrm{P}_{\mathrm{d}}$ pressure data were exported from the catheterisation laboratory. The Volcano and St. Jude systems sampled the invasive pressure data at $200 \mathrm{~Hz}$ and $100 \mathrm{~Hz}$, respectively. The algorithm (developed in MATLAB; MathWorks, Inc., Natick, MA, USA) post-processed the $\mathrm{P}_{\mathrm{a}}$ and $\mathrm{P}_{\mathrm{d}}$ pressure signals over the entire recording from onset of adenosine infusion to the end of the recording. For computing FFR the raw $\mathrm{P}_{\mathrm{d}}$ and $\mathrm{P}_{\mathrm{a}}$ pressure signals were divided into individual cardiac cycles. The beat-by-beat $\mathrm{P}_{\mathrm{d}} / \mathrm{P}_{\mathrm{a}}$ ratio was calculated, and $\mathrm{FFR}_{\text {min }}$ was considered as the minimum value of a three-beat moving average, which is consistent with the typical output of clinical analysers. For computing FFR $_{\text {stable, }}$ a fast Fourier transformation (FFT) decomposed the individual pressure signals in the frequency domain. A low band-pass filter was applied with a $0.04 \mathrm{~Hz}$ threshold, corresponding to a period of $25 \mathrm{~s}$. This eliminated higher frequency components $(>0.04 \mathrm{~Hz})$ of the pressure signals, namely cardiac (typically $\sim 1.0 \mathrm{~Hz}$ ) and respiratory (typically $\sim 0.2 \mathrm{~Hz}$ ) components. Figure 2 shows that this filtering procedure captures the temporal gradients associated with the adenosine response whilst eliminating the unwanted respiratory and cardiac frequencies. The purpose of this filter is to assist the process of identification of a stable period, to avoid confounding by high temporal gradients in the cardiac or respiratory cycle. This could equally have been achieved using a moving average over a defined window. To identify $\mathrm{FFR}_{\text {stable }}$, the $1^{\text {st }}$ derivative of the $\mathrm{P}_{\mathrm{d}} / \mathrm{P}_{\mathrm{a}}$ trace was calculated using a central finite difference scheme using a sampling period of seven seconds. FFR stable $_{\text {was }}$ identified as the average of the $\mathrm{P}_{\mathrm{d}} / \mathrm{P}_{\mathrm{a}}$ ratio during the stable period, identified between the first and last instants where the $1^{\text {st }}$ derivative was below a threshold, after the peak response. The threshold for the $1^{\text {st }}$ derivative was $10^{-5}$, and this was increased in $5 \%$ increments with an upper limit of $2 \times 10^{-3}$.

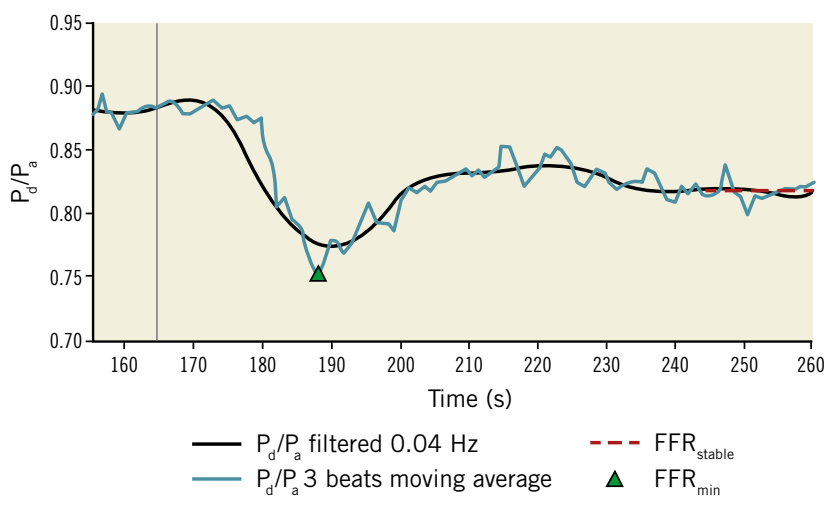

Figure 2. The graphical output of the mathematical algorithm. The algorithm has identified FFR ${ }_{\text {min }}$ from the moving average $P_{d} P_{a}$ (blue line) and FFR stable (red dotted line) from the filtered signal (black line). The vertical grey line indicates the commencement of the adenosine infusion.

In addition to the numerical results, the algorithm provided a graphical analysis of each case, demonstrating the physiological response as a function of time. This was parsed visually to ensure validity of the computed results. An example is illustrated in Figure 2. To demonstrate the effect of signal averaging, ectopic beats and artefact on the FFR result, we analysed the data first averaging every single cardiac cycle and then averaging over two and three cardiac cycles. All computation was performed on a standard office PC (Dell OptiPlex 3020, Intel Core i5, 3.20 GHz, 8GB RAM).

\section{STATISTICAL ANALYSIS}

FFR values were compared by calculating the mean delta (bias). Bland-Altman plots and the limits of agreement $( \pm 1.96$ standard deviation) were plotted ${ }^{12}$. Statistical differences between means were calculated using paired-sample t-tests (assuring normal distribution). Agreeability was assessed by calculating the intra-class correlation coefficient. Data are presented as mean (standard deviation) unless otherwise stated. FFR signal variability was assessed by calculating the mean, standard deviation, range, and coefficient of variation $(\mathrm{CoV})$. The significance of lesion reclassification was assessed with McNemar's test. Statistical analyses were performed using IBM SPSS (IBM Corp., Armonk, NY, USA) and Microsoft Excel (Microsoft Corp., Redmond, WA, USA).

\section{Results \\ CLINICAL DATA}

One hundred and sixty-three coronary artery lesions from 93 patients were studied. Seventy patients were male (75\%), 61 had hypertension $(65.5 \%), 38$ had a history of prior myocardial infarction (40.9\%), and 21 were diabetic $(22.6 \%)$. Mean age was 64.7 years (10.2) and mean BMI was 29.3 (4.7). Lesions were located in 72 left anterior descending, 40 right, 33 left circumflex, 13 diagonal and 5 left main stem coronary arteries. The mean FFR $_{\mathrm{CL}}$ was 0.779 (0.15); 84 lesions (64 patients) were physiologically significant (FFR $\leq 0.80)$ and 79 were non-significant (FFR $>0.80$ ). Patient and lesion characteristics are summarised in Table 1. 
Table 1. Patient and lesion location characteristics. Patient demographics ( $\mathrm{N}=93$ )

\begin{tabular}{|l|c|}
\hline Male & $75.0 \%$ \\
\hline Mean age (years) & 64.7 (SD 10.2) \\
\hline Mean BMI & 29.3 (SD 4.7) \\
\hline Comorbidities & $65 \%$ \\
\hline Hypertension & $5.4 \%$ \\
\hline Peripheral vascular disease & $40.9 \%$ \\
\hline Previous MI & $5.4 \%$ \\
\hline Atrial fibrillation & $22.6 \%$ \\
\hline Type 2 and 1 diabetes & $77.4 \%$ \\
\hline Hyperlipidaemia & \\
\hline Lesion location & $42.9 \%$ \\
\hline Left anterior descending & $24.5 \%$ \\
\hline Right coronary & $19.0 \%$ \\
\hline Left circumflex & $8.6 \%$ \\
\hline Diagonal & $4.9 \%$ \\
\hline Left main stem & \\
\hline BMI: body mass index; MI: myocardial infarction; SD: standard deviation \\
\hline
\end{tabular}

\section{THE ALGORITHM PERFORMANCE}

The algorithm identified the phases of the $\mathrm{P}_{\mathrm{d}} / \mathrm{P}_{\mathrm{a}}$ response during adenosine infusion, irrespective of the presence of tachycardia $(n=5)$, bradycardia $(n=11)$ or atrial fibrillation $(n=5)$ in all cases. An example of a typical result is demonstrated in Figure 2. The algorithm computed results for each case in a mean time of $1.9 \mathrm{~s}$. The results obtained from the algorithm were identical on repeated analysis.

\section{$\mathbf{P}_{\mathrm{d}} / \mathrm{P}_{\mathrm{a}}$ VARIABILITY}

During the period of stable hyperaemia, the $\mathrm{P}_{\mathrm{d}} / \mathrm{P}_{\mathrm{a}}$ signal varied by $2 \%$ (mean coefficient of variation 0.02 [0.01]). The maximum observed variability was $6.3 \%$, the minimum was $0.2 \%$ and $6 \%$ of cases had $\geq 5 \%$ variability. Variability was similar in cases with bradycardia, tachycardia and atrial fibrillation (mean $\mathrm{CoV}=0.01$, 0.01 and 0.02 , respectively). Under baseline conditions, variability in the $\mathrm{P}_{\mathrm{d}} / \mathrm{P}_{\mathrm{a}}$ ratio was $0.7 \%$ (mean $\mathrm{CoV}=0.007$ [0.017]).

\section{SIGNAL PROCESSING}

The number of cardiac cycles over which $\mathrm{P}_{\mathrm{d}} / \mathrm{P}_{\mathrm{a}}$ data were averaged had an effect on $\mathrm{FFR}_{\text {min }}$. FFR ${ }_{\text {min }}$ was lowest when the $\mathrm{P}_{\mathrm{d}} / \mathrm{P}_{\mathrm{a}}$ signal was averaged over individual cardiac cycles. As the number of cycles increased from one to two to three beats, the $\mathrm{P}_{\mathrm{d}} / \mathrm{P}_{\mathrm{a}}$ signal became smoother and the mean $\mathrm{FFR}_{\min }$ increased marginally (0.746 [0.17] vs. 0.757 [0.16] vs. 0.762 [0.16]: $p<0.001$ for all comparisons). Cardiac cycle averaging also affected the physiological classification of lesions: 1-beat, 2-beat and 3-beat averaging resulted in $58 \%, 56 \%$ and $55 \%$ of lesions being classified as physiologically significant, respectively.

\section{COMPARING MEAN VALUES OF FFR ${ }_{\text {min }}$, FFR $_{\text {stable }}$ AND FFR} As demonstrated in the Bland-Altman plot (Figure $3 A$ ), $\mathrm{FFR}_{\text {min }}$ was consistently lower than $\mathrm{FFR}_{\text {stable }}(0.762$ [0.16] vs. 0.806 [0.15], $\mathrm{p}<0.001)$. The intra-class correlation coefficient between $\mathrm{FFR}_{\text {min }}$ and $\mathrm{FFR}_{\text {stable }}$ was 0.986 (95\% CI: 0.98-0.99, p<0.001). As demonstrated in the Bland-Altman plots (Figure 3B, Figure 3C), $\mathrm{FFR}_{\mathrm{CL}}$ was higher than FFR $_{\min }(0.779$ [0.15] vs. 0.762 [0.16], p<0.001) but lower than FFR ${ }_{\text {stable }}(0.806$ [0.15], $\mathrm{p}<0.001)$. The intra-class correlation coefficient between $\mathrm{FFR}_{\mathrm{CL}}$ and $\mathrm{FFR}_{\text {min }}$ was $0.990(95 \%$ CI: $0.99-0.99, \mathrm{p}<0.001)$ and between $\mathrm{FFR}_{\mathrm{CL}}$ and $\mathrm{FFR}_{\text {stable }}$ was 0.987 (95\% CI: 0.98-0.99, $\mathrm{p}<0.001)$.

\section{IMPACT OF OBJECTIVE ANALYSIS ON CLASSIFICATION OF LESION SIGNIFICANCE}

With FFR $_{\text {min }}$ taken as arbiter of lesion significance, 92 lesions $(56.4 \%)$ were classified as physiologically significant and 71 (43.6\%) non-significant. With FFR ${ }_{\text {stable }}$ as arbiter, 65 lesions (39.8\%) were significant and 98 (60.2\%) were non-significant. Thus, using $\mathrm{FFR}_{\text {stable }}$ instead of $\mathrm{FFR}_{\text {min }}$ resulted in $16.5 \%$ of all lesions (27 lesions,
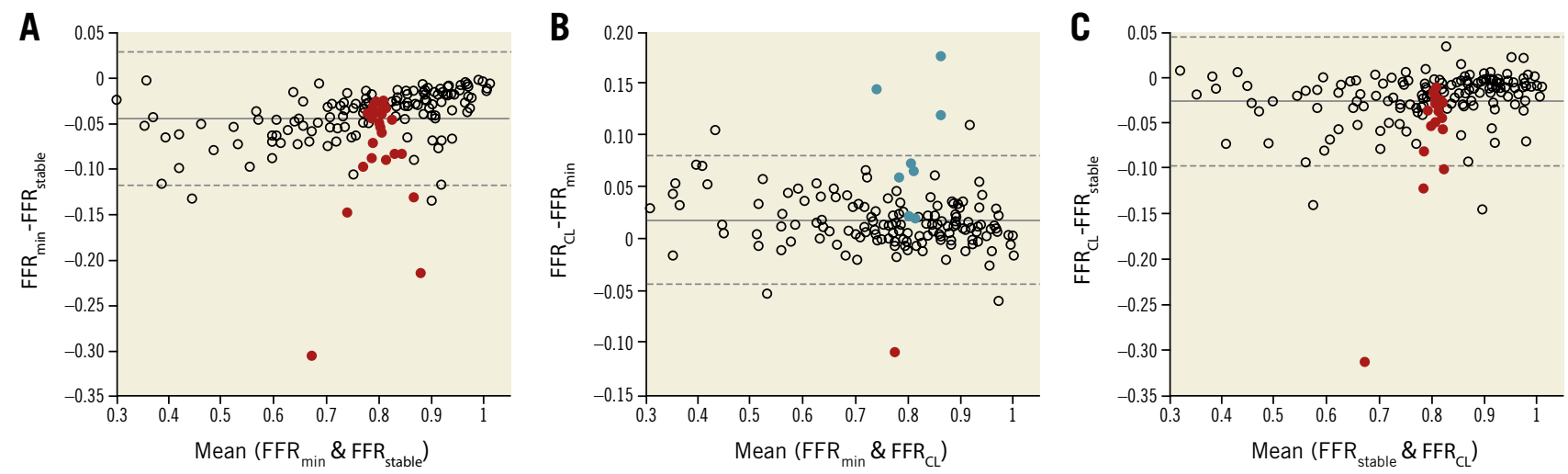

Figure 3. Bland-Altman plots demonstrating the differences between $F F R_{\text {min }}$, FFR ${ }_{\text {stable }}$ and $F F R_{C L}$. The unbroken horizontal lines represent the bias (mean delta) and the dashed horizontal lines represent the limits of agreement $\left( \pm 1.96 S D\right.$ around the mean). A) FFR ${ }_{\text {min }} v S . F F R_{\text {stable' }}$ bias $=0.044 \pm 0.07$. B) $F F R_{C L} v s . F F R_{\text {min }^{\prime}}$, bias $=0.017 \pm 0.06$. C) $F F R_{C L} v s . F F R_{\text {stable }}$, bias $=0.03 \pm 0.07$. Coloured dots indicate lesions which crossed the threshold of physiological significance $(\leq 0.80)$ and were reclassified as a result of the different methods. Red indicates cases changing from significant to non-significant and blue indicates cases moving from non-significant to significant. 
23 patients) being reclassified from significant to non-significant $(\mathrm{p}<0.01)$. With $\mathrm{FFR}_{\mathrm{CL}}$ as arbiter of lesion significance, 84 lesions (51.5\% lesions) were deemed to be physiologically significant and 79 (48.5\%) non-significant. Compared with FFR ${ }_{\text {min }}$, using FFR $_{\mathrm{CL}}$ as arbiter resulted in $6.1 \%$ of all lesions (ten lesions, eight patients) being reclassified $(\mathrm{p}<0.01)$, nine from significant to non-significant (5.5\% of all lesions and seven patients) and one from non-significant to significant $(0.6 \%$ of all lesions, one patient). Compared with $\mathrm{FFR}_{\text {stable }}$, use of $\mathrm{FFR}_{\mathrm{CL}}$ resulted in $11.7 \%$ of all lesions being reclassified $(\mathrm{p}<0.01)$, all from significant to non-significant (19 lesions, 17 patients). These data are illustrated in Figure 4.

\section{RESPONSE TO ADENOSINE}

Careful visual analysis of all cases demonstrated a lack of a truly stable hyperaemic phase in eleven cases $(6.7 \%$ of all lesions, seven patients). In these cases, the $\mathrm{P}_{\mathrm{d}} / \mathrm{P}_{\mathrm{a}}$ signal fell and then rose continually. The nature of the algorithm is such that it will always identify and report the most stable period of this signal as FFR $_{\text {stable }}$. However, in view of this, we re-analysed the results with these cases excluded. The results were not significantly different. Mean FFR ${ }_{\text {min }}, \mathrm{FFR}_{\text {stable }}$ and $\mathrm{FFR}_{\mathrm{CL}}$ were $0.760(0.16), 0.799(0.15)$ and $0.776(0.15)$, respectively ( $<<0.05$ for all comparisons). With $\mathrm{FFR}_{\text {min }}, \mathrm{FFR}_{\text {stable }}$ and $\mathrm{FFR}_{\mathrm{CL}}$ as arbiter of physiological lesion classification, the number of significant lesions was $57.2 \%, 42.1 \%$ and 52.6\%, respectively. Betweengroup reclassification of physiological significance was also similar, with $<1 \%$ difference for all like-for-like comparisons.

\section{TIME TO PEAK AND STABLE HYPERAEMIA}

The mean time taken to reach $\mathrm{FFR}_{\text {min }}$ was $55 \mathrm{~s}(19)$ and the range was $17-131 \mathrm{~s}$. The mean time taken to reach FFR $_{\text {stable }}$ was $69 \mathrm{~s}$ (18) and the range was $37-140 \mathrm{~s}$.

\section{Discussion}

We have developed an algorithm that objectively identifies FFR during peak $\left(\mathrm{FFR}_{\text {min }}\right)$ and stable hyperaemic periods $\left(\mathrm{FFR}_{\text {stable }}\right)$. The algorithm is based on a combination of simple filtering methods selected to highlight, in a repeatable and objective manner, the key characteristics of the hyperaemic response. The algorithm analysed all cases in less than two seconds and provided identical results with repeated analysis. $\mathrm{FFR}_{\text {min }}$ was consistently lower than $\mathrm{FFR}_{\text {stable }}$ Although the absolute difference was modest $\left(0.76\right.$ for $\mathrm{FFR}_{\min }$ vs. 0.81 for $\mathrm{FFR}_{\text {stable }}$ ), it was consistent, statistically significant and had a substantial impact on the classification of physiological lesion significance. Compared with $\mathrm{FFR}_{\text {min }}$, when $\mathrm{FFR}_{\text {stable }}$ was applied, 16.5\% of all lesions were reclassified, all from significant to non-significant.

Our findings are important, given the role of FFR in guiding treatment decisions, especially in cases in which FFR is close to the decision threshold. The proportion of cases reclassified depends upon the number of cases in the group studied which are clustered near the 0.80 threshold. Our cases were selected on the basis of stenoses being $50-90 \%$ by visual analysis, not on being physiologically "borderline", and are therefore realistic and applicable within real-world practice. The methods used are applicable to all commercially available pressure wires.

In contrast to other studies, we compared the operator-selected FFR $\left(\mathrm{FFR}_{\mathrm{CL}}\right)$ with the algorithm-derived results. $\mathrm{FFR}_{\mathrm{CL}}$ was higher than $\mathrm{FFR}_{\text {min }}$ but lower than $\mathrm{FFR}_{\text {stable }}$. Importantly, $\mathrm{FFR}_{\mathrm{CL}}$ classified lesions differently from both $\mathrm{FFR}_{\text {min }}$ and $\mathrm{FFR}_{\text {stable }}$. Compared with $\mathrm{FFR}_{\mathrm{CL}}, \mathrm{FFR}_{\text {stable }}$ resulted in $11.7 \%$ of lesions being reclassified, all from significant to non-significant. Compared with $\mathrm{FFR}_{\mathrm{CL}}$, use of $\mathrm{FFR}_{\text {min }}$ resulted in $6.1 \%$ of all lesions being reclassified, mostly from non-significant to significant. In short, all three approaches result in discordant treatment guidance.

The FFR signal was not completely steady, even during "stable" hyperaemia. During stable hyperaemia, variability was small (CoV $2 \%$ ) but was sufficient to introduce uncertainty into the interpretation of FFR, especially in cases close to the threshold. Variability was higher in some cases ( $>5 \%$ in $6 \%$ of cases). Variability was lower under baseline conditions (0.7\%). Although FFR cannot be compared directly with iFR, this may reflect a more stable condition for physiological analysis ${ }^{6,13}$. Mean time to reach $\mathrm{FFR}_{\min }$ and FFR $_{\text {stable }}$ was consistent with other published data ${ }^{8}$.
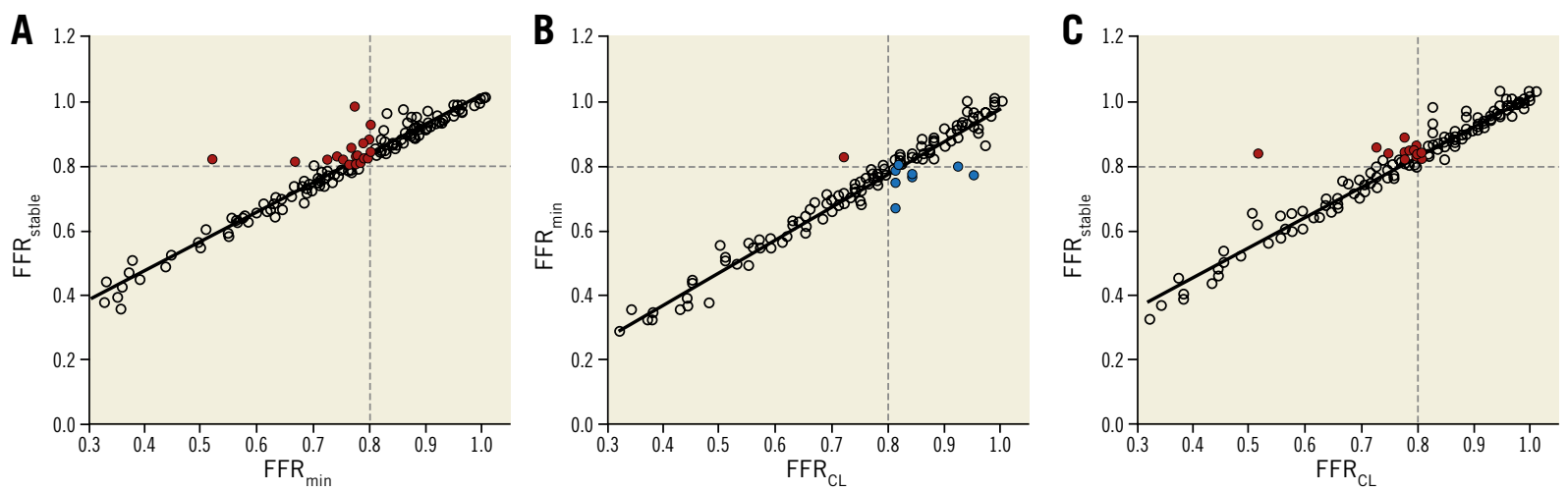

Figure 4. Scatter plots demonstrating the relationship between $F F R_{\text {min }}, F F R_{\text {stable }}$ and $F F R_{C L}$. The coloured dots indicate lesions classified

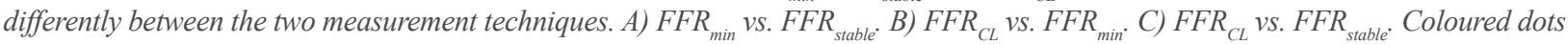
indicate lesions which crossed the threshold of physiological significance $(\leq 0.80)$ and were reclassified as a result of the different methods. Red indicates cases changing from significant to non-significant and blue indicates cases moving from non-significant to significant. 
We are not the first group to highlight the difference between $\mathrm{FFR}_{\text {min }}$ and $\mathrm{FFR}_{\text {stable }}{ }^{6,10}$. Tarkin et al analysed $\mathrm{P}_{\mathrm{d}} / \mathrm{P}_{\mathrm{a}}$ tracings, demonstrating a similar mean delta $(+0.04)$ but with lower rates of lesion reclassification ( $9 \%$ vs. $16.5 \%$ ). In a subsequent analysis, the same group demonstrated a smaller rise from $\mathrm{FFR}_{\text {min }}$ to $\mathrm{FFR}_{\text {stable }}(+0.006)$ and a lower rate of lesion reclassification $(2.9 \%)$. The authors supported the routine use of FFR $\mathrm{Ftable}_{\text {e }}$ as the "true" FFR. Neither paper separately quoted the operator-selected FFR. A study of 52 patients by Seto et al demonstrated variability in the $\mathrm{P}_{d} / \mathrm{P}_{\mathrm{a}}$ signal during FFR measurement ${ }^{7}$. They compared $\mathrm{FFR}_{\min }$ to the highest subsequent $\mathrm{P}_{\mathrm{d}} / \mathrm{P}_{\mathrm{a}}$ ratio recorded during the period of adenosine infusion. Although the methods are not directly comparable, they demonstrated a greater overall difference $(+0.08)$ in FFR and a higher rate of lesion reclassification (28\%). Johnson et al also used a mathematical algorithm to identify what they termed the "smart minimum" FFR to demonstrate the repeatability of FFR on consecutive invasive measurements ${ }^{8}$. Matsumura et al compared site-reported FFR with core laboratory analysis. A significant number of cases were excluded from the final analysis due to signal drift $(17.5 \%)$, ventricularisation of the pressure signal (5.3\%) and waveform distortion (4.0\%). After exclusions, site-reported FFR differed from core laboratory analysis by $+0.003( \pm 0.02)$, with Bland-Altman limits of agreement of \pm 0.04 . Contrary to our study, neither analysis was algorithmic, and the study did not specifically analyse or compare the period of stable hyperaemia. Both studies, however, reinforce the need for a careful and consistent approach when analysing FFR. An algorithmic approach may aid this.

The principal advantage of FFR over visual CAG assessment is its objectivity. Our algorithm extends this, removing any remaining bias and/or subjectivity in interpretation and negating the need to "choose" the FFR. Even if there is microvascular dysfunction, with a blunting of $\mathrm{P}_{\mathrm{d}} / \mathrm{P}_{\mathrm{a}}$, our algorithm will still identify the nadir of the response and the most stable subsequent period. Given similar input data, the algorithm always returns the same result with zero intra- or inter-observer variability and is unaffected by variability in the FFR signal.

In the current study, we observed a variable $\mathrm{P}_{\mathrm{d}} / \mathrm{P}_{\mathrm{a}}$ response during adenosine infusion. The lack of a predictable, stereotyped response has important implications for those seeking to develop predictive computational models of "virtual" FFR, because the accuracy of such models is heavily dependent upon assumptions made about the microvascular physiology which dictates the nature and magnitude of the hyperaemic response ${ }^{14}$. Moreover, the fact that subtle differences in how FFR was defined and assessed had such a significant impact on lesion classification means that it is unlikely that computational models will achieve $100 \%$ accuracy relative to a meticulously performed invasive measurement conforming to our algorithm.

In 2016, a group including the pioneers of FFR measurement published a manuscript aiming to standardise FFR measurement ${ }^{11}$. They suggested that FFR should be taken as "the level of the nadir of the $\mathrm{P}_{\mathrm{d}} / \mathrm{P}_{\mathrm{a}}$ tracing" but emphasised the need for "manual control" and "fine-tuning" in order to mitigate the effects of artefact in either the coronary or the arterial pressure recordings. Also of relevance is the demonstration that the minimum $\mathrm{P}_{\mathrm{d}} / \mathrm{P}_{\mathrm{a}}\left(\mathrm{FFR}_{\min }\right)$ achieved during intravenous infusion of adenosine shows good agreement with that achieved with the intracoronary administration of a bolus of adenosine, both measures being highly reproducible ${ }^{8}$. The current

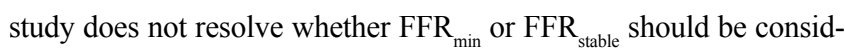
ered the "true" FFR. Instead, we have demonstrated objectively that each approach results in different patterns of physiological classification. Moreover, the FFR selected by the operator results in a different pattern of lesion classification again. A consensus is required. Intuitively, the same measurement technique should be applied as was applied in the seminal trials which pioneered FFR and resulted in the currently applied threshold. Although recent guidance advises that the "nadir of the $\mathrm{P}_{\mathrm{d}} / \mathrm{P}_{\mathrm{a}}$ tracing" should be used", previous trials state that FFR was acquired during "steady-state hyperaemia"15, "maximal hyperaemia"16 and "adenosine-induced hyperaemia". There are merits for both approaches. Given the difficulty in identifying stable hyperaemia in some $(6.7 \%)$ cases, even with an algorithmic approach, this study pragmatically supports the use of $\mathrm{FFR}_{\min }$.

\section{Limitations}

This study focused on patients undergoing FFR with intravenous adenosine as the hyperaemic stimulus because this is the commonest and most established method of evaluating physiological lesion severity in the cardiac catheterisation laboratory. Adenosine can also be given via an intracoronary route or alternative agents such as papaverine can be used. These alternative methods were not considered. This was a single-centre study. A larger multicentre trial would be needed to discover whether the effect on lesion reclassification is maintained.

\section{Conclusions}

We have shown that an algorithmic analysis simplifies interpretation of the FFR signal, eradicates variability and subjectivity, and provides a $100 \%$ objective result which may be useful in a standardised assessment of FFR. Differences in how FFR is defined and assessed significantly impact on the FFR result and the classification of physiological lesion significance.

\section{Impact on daily practice}

Subtle differences in how and when FFR is measured in the cardiac catheterisation laboratory have a significant impact on how lesions are classified physiologically. Variability may occur at the level of the system or the operator. Use of an automated algorithm eradicates variability and subjectivity and may be useful in a standardised assessment of FFR.

\section{Acknowledgements}

The authors are grateful to Mrs Tina Hook (Sheffield Teaching Hospitals) for her help and expertise in ensuring absolute precision in our physiological data collection. 


\section{Funding}

P.D. Morris and R. Gosling were funded by Research Training Fellowships (British Heart Foundation). P.D. Morris was subsequently funded by an NIHR Clinical Lectureship. M.I. Sciola was funded by a studentship from the Engineering and Physical Sciences Research Council. Clinical data were generated with support from the Wellcome Trust and Department of Health, UK (R/135171-11-1). The views expressed in this publication are those of the authors and not necessarily those of the funding bodies, NHS, the NIHR or the Department of Health.

\section{Conflict of interest statement}

The authors have no conflicts of interest to declare.

\section{References}

1. Topol EJ, Nissen SE. Our preoccupation with coronary luminology. The dissociation between clinical and angiographic findings in ischemic heart disease. Circulation. 1995;92:2333-42.

2. Mintz GS, Popma JJ, Pichard AD, Kent KM, Satler LF, Chuang YC, DeFalco RA, Leon MB. Limitations of angiography in the assessment of plaque distribution in coronary artery disease: a systematic study of target lesion eccentricity in 1446 lesions. Circulation. 1996;93:924-31.

3. Pijls NH, Van Gelder B, Van der Voort P, Peels K, Bracke FA, Bonnier HJ, el Gamal MI. Fractional flow reserve. A useful index to evaluate the influence of an epicardial coronary stenosis on myocardial blood flow. Circulation. 1995;92:3183-93.

4. De Bruyne B, Baudhuin T, Melin JA, Pijls NH, Sys SU, Bol A, Paulus WJ, Heyndrickx GR, Wijns W. Coronary flow reserve calculated from pressure measurements in humans. Validation with positron emission tomography. Circulation. 1994;89:1013-22.

5. De Bruyne B, Pijls NH, Kalesan B, Barbato E, Tonino PA, Piroth Z, Jagic N, Mobius-Winckler S, Rioufol G, Witt N, Kala P, MacCarthy P, Engström T, Oldroyd KG, Mavromatis K, Manoharan G, Verlee P, Frobert O, Curzen N, Johnson JB, Jüni P, Fearon WF; FAME 2 Trial Investigators. Fractional flow reserveguided PCI versus medical therapy in stable coronary disease. N Engl J Med. 2012;367:991-1001.

6. Tarkin JM, Nijjer S, Sen S, Petraco R, Echavarria-Pinto M, Asress KN, Lockie T, Khawaja MZ, Mayet J, Hughes AD, Malik IS, Mikhail GW, Baker CS, Foale RA, Redwood S, Francis DP, Escaned J, Davies JE. Hemodynamic response to intravenous adenosine and its effect on fractional flow reserve assessment: results of the Adenosine for the Functional Evaluation of Coronary Stenosis Severity (AFFECTS) study. Circ Cardiovasc Interv. 2013;6: 654-61.
7. Seto AH, Tehrani DM, Bharmal MI, Kern MJ. Variations of coronary hemodynamic responses to intravenous adenosine infusion: implications for fractional flow reserve measurements. Catheter Cardiovasc Interv. 2014;84:416-25.

8. Johnson NP, Johnson DT, Kirkeeide RL, Berry C, De Bruyne B, Fearon WF, Oldroyd KG, Pijls NH, Gould KL. Repeatability of Fractional Flow Reserve Despite Variations in Systemic and Coronary Hemodynamics. JACC Cardiovasc Interv. 2015;8: 1018-27.

9. De Bruyne B, Sarma J. Fractional flow reserve: a review: invasive imaging. Heart. 2008;94:949-59.

10. Echavarria-Pinto M, Petraco R, van de Hoef TP, Gonzalo N, Nijjer S, Tarkin JM, Ibanez B, Sen S, Jimenez-Quevedo P, NunezGil IJ, Nombela-Franco L, Alfonso F, Fernandez-Ortiz A, Macaya C, Piek JJ, Davies J, Escaned J. Fractional flow reserve and minimum $\mathrm{P}_{\mathrm{d}} / \mathrm{P}_{\mathrm{a}}$ ratio during intravenous adenosine infusion: very similar but not always the same. EuroIntervention. 2016;11:1013-9.

11. Toth GG, Johnson NP, Jeremias A, Pellicano M, Vranckx P, Fearon WF, Barbato E, Kern MJ, Pijls NH, De Bruyne B. Standardization of Fractional Flow Reserve Measurements. $\mathrm{J} \mathrm{Am}$ Coll Cardiol. 2016;68:742-53.

12. Bland JM, Altman DG. Statistical methods for assessing agreement between two methods of clinical measurement. Lancet. 1986;1:307-10.

13. Sen S, Escaned J, Malik IS, Mikhail GW, Foale RA, Mila R, Tarkin J, Petraco R, Broyd C, Jabbour R, Sethi A, Baker CS, Bellamy M, Al-Bustami M, Hackett D, Khan M, Lefroy D, Parker KH, Hughes AD, Francis DP, Di Mario C, Mayet J, Davies JE. Development and validation of a new adenosine-independent index of stenosis severity from coronary wave-intensity analysis: results of the ADVISE (ADenosine Vasodilator Independent Stenosis Evaluation) study. J Am Coll Cardiol. 2012;59:1392-402.

14. Morris PD, Silva Soto DA, Feher JFA, Rafiroiu D, Lungu A, Varma S, Lawford PV, Hose DR, Gunn JP. Fast Virtual Fractional Flow Reserve Based Upon Steady-State Computational Fluid Dynamics Analysis: Results From the VIRTU-Fast Study. JACC Basic Transl Sci. 2017;2:434-46.

15. Pijls NH, De Bruyne B, Peels K, Van Der Voort PH, Bonnier HJ, Bartunek J Koolen JJ, Koolen JJ. Measurement of fractional flow reserve to assess the functional severity of coronaryartery stenoses. N Engl J Med. 1996;334:1703-8.

16. Tonino PA, De Bruyne B, Pijls NH, Siebert U, Ikeno F, van' t Veer M, Klauss V, Manoharan G, Engstrom T, Oldroyd KG, Ver Lee PN, MacCarthy PA, Fearon WF; FAME Study Investigators. Fractional flow reserve versus angiography for guiding percutaneous coronary intervention. N Engl J Med. 2009;360:213-24. 